Original Research Paper

\title{
Effects of Playing Surface and Shoe Type on ACL Tears in Soccer Players
}

\author{
${ }^{1}$ Melissa M. Mansfield and ${ }^{2}$ Ronald B. Bucinell \\ ${ }^{1}$ Binghamton University, Mechanical Engineering, Vestal, NY, USA \\ ${ }^{2}$ Union College, Mechanical Engineering, Schenectady, NY, USA
}

\author{
Article history \\ Received: 03-11-2016 \\ Revised: 07-12-2016 \\ Accepted: 13-12-2016 \\ Corresponding Author: \\ Melissa M. Mansfield \\ Binghamton University, \\ Mechanical Engineering, Vestal, \\ NY, USA \\ Email: mmansfi1@binghamton.edu
}

\begin{abstract}
Today, Anterior Cruciate Ligament (ACL) tears are one of the most prevalent knee injuries, with the occurrence of ACL tears increasing drastically from approximately 80000 in 2000 to 150000 in 2011 . Although there are many factors that contribute to an ACL tear occurring, certain environmental factors could contribute to the dramatic increase over the past couple decades, especially in athletes. This study explores two of these possible factors; the playing surface and the type of shoes worn by soccer players. The effects these factors have on ACL tears were evaluated by measuring the maximum torque achieved prior to the shoe breaking free of the playing surface using a servo-hydraulic bi-axial load frame. A prosthetic foot fitted into various soccer shoes was fixed to the load cell and different playing surface samples were fixed to the actuator of the load frame. Axial loads were applied to simulate an athlete's body weight and rotations were applied to simulate an athlete pivoting on that playing surface. The maximum torque achieved prior to the soccer shoe slipping on the playing surface was measured. Out of the shoes tested, this investigation finds that wearing round study cleats or turf shoes on artificial turf surfaces provides the best traction for maneuvers in games while still allowing the shoe to slip when more dangerous torque levels are reached. Additionally, grass surfaces were found to be safer than artificial turf surfaces, as grass has the ability to deform or break to maintain a threshold torque value, making it less likely for the torque to reach higher values associated with ACL injury.
\end{abstract}

Keywords: Anterior Cruciate Ligament, Ligament Torque, Surface Traction, Artificial Turf, Natural Surface, Playing Surface

\section{Introduction}

Anterior Cruciate Ligament (ACL) tears are one of the most prevalent knee injuries in the world today, especially in the athletic community. The American Orthopedic Society for Sports Medicine (AOSSM) reported approximately 150000 ACL injuries occurred in the United States in 2011 alone (Coleman, 2011). This is a drastic increase from the estimated 80000 ACL tears reported in 2000 (Griffin et al., 2000).

Although there are many factors that contribute to ACL injuries, the use of artificial turf surfaces has been a topic of great debate. There are many benefits to using artificial turf surfaces; however, many people believe that the increased use of these surfaces over natural surfaces could be a large contributing factor to the dramatic increase in ACL tears over the past couple decades.
Previous studies have investigated the effects of shoe type and playing surfaces on rotational traction which is associated with ACL injury using portable testing equipment (Serensits and McNitt, 2014; Villwock et al., 2009). These studies have conflicting results pertaining to the effects of playing surface on rotational traction, further adding to the debate. These inconsistencies in data could be due to limitations with portable testing equipment and the inability to create reproducible tests conditions.

This study uses the approach previously reported by Morse et al. (2016) for hard court shoe traction which uses a servo-hydraulic bi-axial load frame to measure the maximum torque achieved between the shoes and playing surfaces under controlled testing conditions. This data is used to determine which shoe and playing surface puts athletes at the least and greatest risk of suffering an ACL injury. 


\section{Materials and Methods}

An experimental study was conducted to directly measure the maximum torque applied to a foot fitted with various soccer shoes prior to slipping on artificial and natural surfaces. The experimental procedures used in this study are consistent with ASTM (2009). First test fixtures for the shoes and turf were designed and constructed, second the test parameters and sequencing of testing were established and third a test procedure was written to insure statistically significant results.

\section{Experimental Set-up}

The main objective for the design of the experimental set up was to accurately and consistently simulate the loading of a player pivoting on a playing surface. This type of loading includes the player's body weight (axial), inertial load (axial) and the torque generated by the pivoting motion. This bi-axial load profile motived the use of a servo-hydraulic bi-axial (axial-torsion) load frame. The experimental set up used in this investigation is shown in Fig. 1.

A test fixture was designed to interface a $\mathrm{SACH}$ (Solid Ankle Cushioned Heel) type prosthetic foot with the hydraulic grips that are attached to the load cell of the load frame. The prosthetic foot was inserted into representative soccer shoes as shown in Fig. 2. The fixture was designed to keep the heel elevated so all of the load was transmitted through only the forefoot during testing. This was done to comply with ASTM standard F2333 (ASTM, 2009).

A second test fixture, the Actuator Interface Plate (AIP), was designed to interface the Mounting Box (shown in Fig. 1) with the hydraulic actuator of the load frame. The AIP is shown in Fig. 3 fixed to the hydraulic grip of the load frame. The holes in the AIP are sized for the pins protruding from the underside of the Mounting Box (shown in Fig. 3). These pins allow the torque generated by the actuator to be transferred to the mounting box, through the turf to the shoe. The hole pattern in the AIP is designed to allow for adjustment of the Mounting box to maximize range of motion. The Mounting Box is designed to allow the Grass Boxes (shown in Fig. 4) and Turf Frames (shown in Fig. 5) to be easily mounted in the load frame during the experimental program.

Both natural and artificial turfs were evaluated in this study. For the natural turfs, Grass Boxes were constructed to fit into the Mounting Box and allow the turf to grow and root as it would on a natural playing surface. For the artificial turfs, Artificial Turf Frames needed to be constructed that fit into the Mounting Box and allowed the artificial turf surface to be mounted in a manner similar to that of an actual playing surface.

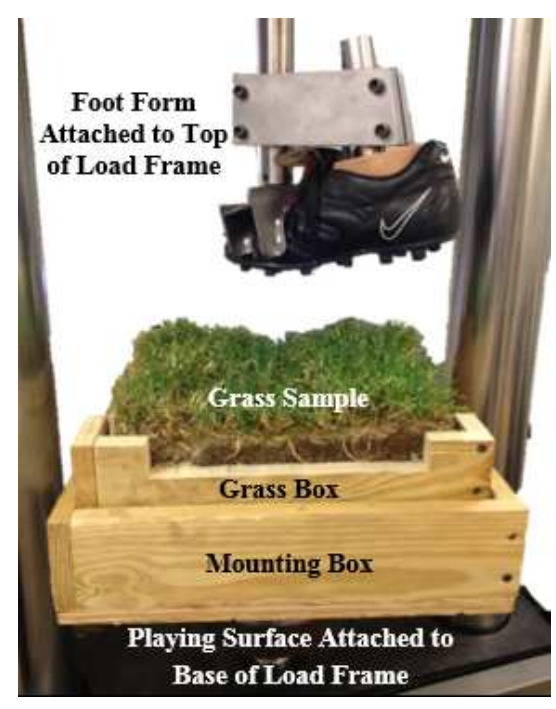

Fig. 1. Experimental set up showing a round studded cleat and grass playing surface sample installed in the bi-axial servo-hydraulic load frame

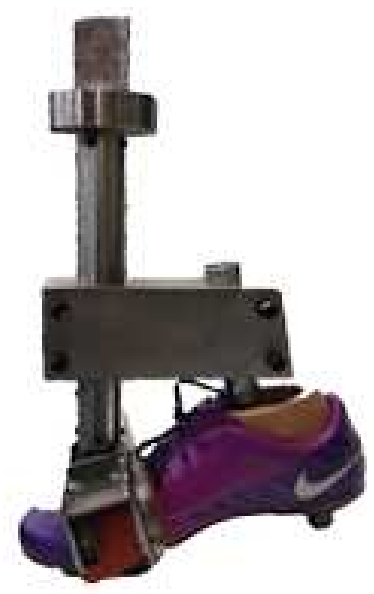

Fig. 2. The fixture used to anchor the foot form to the bi-axial servo-hydraulic load frame. The fixture allows all the load to be transmitted through the forefoot in accordance with ASTM standards

The natural turf used in this study was Kentucky Bluegrass grown in wood boxes (referred to as Grass Boxes) that contained $50 \mathrm{~mm}$ ( 2 in.) of soil and a wire mesh to help anchor the grass roots (Fig. 4). Due to time considerations, the grass samples had a limited time to grow. Wire mesh was incorporated so the roots could grow through the mesh and help anchor the grass samples to better simulate actual playing surface conditions. The grass samples were watered daily and cut weekly. A special box with a hinged side was created, so root development could be monitored. The roots were fully developed before testing which was seen by the lack of new white colored roots. 


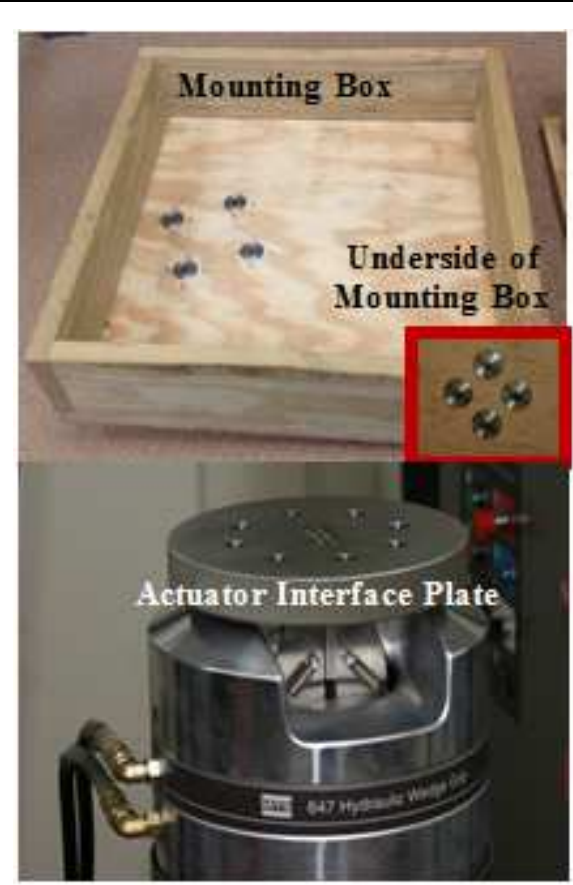

Fig. 3. The Actuator Interface Plate and Mounting Box designed to transfer torque from the hydraulic actuator through the turf to the shoe during the experimental trials

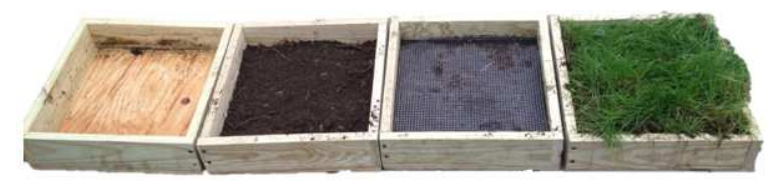

Fig. 4. The process followed to make the grass samples consisting of a wood box filled with $50 \mathrm{~mm}$ ( 2 in.) of soil, a wire mesh and Kentucky Bluegrass sod

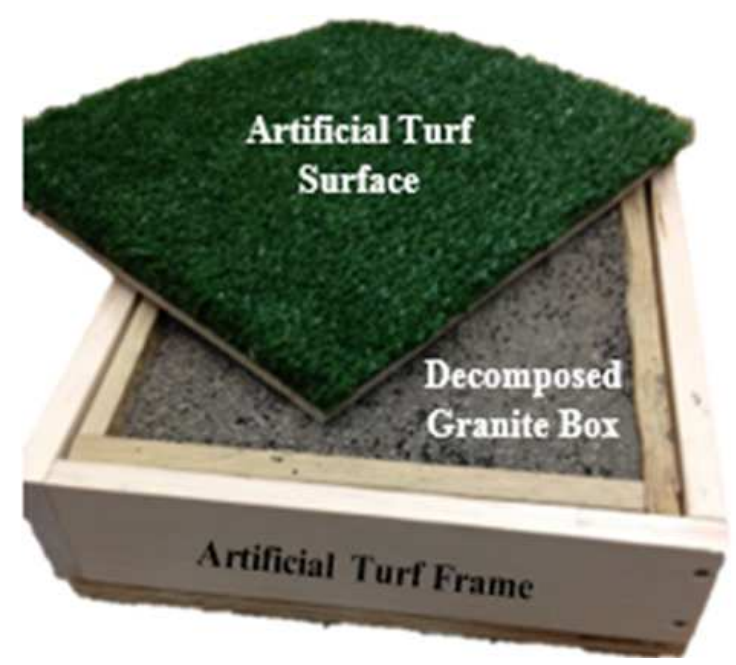

Fig. 5. Shows how the artificial turf frame fits around the decomposed granite box. Note that the shown picture is before the artificial turf surface was nailed to the frame. This whole setup fits inside the mounting box for testing
Since there was limited space to store and grow the grass samples, the experimental set-up was designed in such a way that one grass sample could be tested four times. This was achieved by rotated the grass boxes in the mounting box by $90^{\circ}$ after each test. This subjected an untested section of grass to torque without changing out the Grass Box.

The artificial surfaces were mounted in Artificial Turf Frames (Fig. 5) that were filled with decomposed granite (referred to as the Decomposed Granite Box) to simulate the foundation used in actual playing field installations. The Decomposed Granite Box (DGB) had $50 \mathrm{~mm}$ ( 2 in.) of coarse decomposed granite with $50 \mathrm{~mm}$ (2 in.) of fine decomposed granite on top which replicates the base found under artificial turf playing fields. The DGB was designed to sit firmly inside the mounting box, while leaving a gap for the artificial turf frames to sit in.

The artificial turf samples were created by nailing pieces of turf to a wood frame. This frame fits between the mounting box and the decomposed granite box and allows the underside of the artificial turf samples to come in complete contact with the decomposed granite (Fig. 5). Metal flashing was anchored to the perimeter of the Artificial Turf Frames to contain the rubber infill that is used in artificial turf applications.

The flashing was used to prevent the infill from being pushed out of the sample in order to maintain the infill depth.

\section{Design of Experiment}

Two parameters were considered in this experimental study, type of soccer shoe (Shoe Type) and the type of playing surface (Playing Surface). The design of this experiment included four categories of Shoe: Turf Shoes, Round Studded, Bladed Studded and Soft Ground cleats (Fig. 6).

There were five categories of Surface: Soil-based Kentucky bluegrass (Grass), thatched artificial turf with $12.5 \mathrm{~mm}$ (1/2") blades and foam backing (Gym Turf), ten-year-old slit film artificial turf with rubber infill (Old Turf) and a new slit film artificial turf surface with 25 mm (1") deep rubber infill (New Turf 1") and $38 \mathrm{~mm}$ (1.5") deep rubber infill (New Turf 1.5"). The Grass Surface is shown in Fig. 4 and the artificial turf surfaces are shown in Fig. 7.

A full factorial design of experiments (Box et al., 2005) was employed with five replicates. Thus the total number of experiments performed:

\begin{tabular}{llccc} 
Shoe Type & Playing Surfaces & \multicolumn{2}{c}{ Replicates } \\
4 & $\times$ & 5 & $\times$ & 5
\end{tabular}$=100$

The testing order was designed to be as random as possible to decrease the chance of trends in the data being 
formed by uncertainties in the testing apparatus; however, due to time restraints, all of the Grass samples had to be tested first without mixing any turf samples into the order (20 tests). To randomize these tests, each grass box was tested once and then switched out for another grass box, until all five grass boxes had been tested once. These boxes were switched in this manner four more times until each box was tested five times. Each time a box was tested, the orientation was rotated so that no spot of grass was tested twice. The order that the shoes were tested on the grass samples was also randomized. The shoes were tested in sets, switching shoes after every two or three trials. In addition, the testing order of the shoes was randomized in way that a certain shoe was not tested after another shoe two separate times.

The four remaining turf samples (Gym Turf, Old Turf, New Turf 1.0" and New Turf 1.5") were tested in two sets since the New Turf sample first had to be tested with $25 \mathrm{~mm}$ (1.0") rubber infill and then $38 \mathrm{~mm}$ (1.5") rubber infill (40 tests per set). This was accomplished by randomly testing half of the Gym Turf and Old Turf samples with all of the New Turf 1.0" samples in the first set, then testing the remaining Gym Turf and Old Turf samples with all of the New Turf 1.5" samples. The shoes being tested were switched after every five trials and the playing surface samples were randomly alternated. The shoe testing was organized in a way where once again, the same shoe would not be tested after another type of shoe every time.

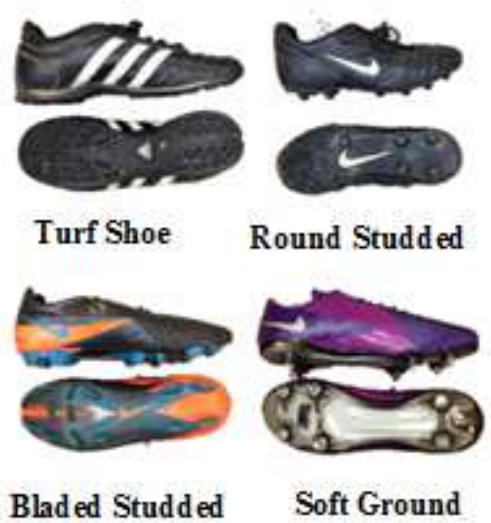

Fig. 6. The four categories of shoes tested

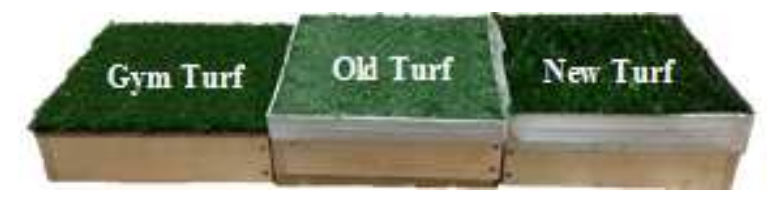

Fig. 7. The artificial turf surfaces attached to wood frames for testing. Note that the shown New Turf sample was tested with $25 \mathrm{~mm}(1 ")$ and $38 \mathrm{~mm}(1.5 ")$ deep rubber infill

\section{Experimental Procedures}

Each of the 100 experimental trials followed the same experimental procedure. First the axial actuator of the load frame shown in Fig. 1 was raised to apply the desired axial load as measured by the load frames load cell. The frame was then set to maintain this position throughout the test. Then under displacement control, the playing surfaces were rotated at a rate of $45 \%$ as specified by ASTM Standard F2333 (ASTM, 2009) and the torque generated by the shoe interacting with the turf was measured using the load frame's load cell. Samples were rotated $45^{\circ}$ due to limited space between the vertical columns of the load frame and to reduce error due to deformation of the shoe at greater rotations. Axial load, axial displacement, torque and torsional displacement were electronically recorded at a sampling rate of 100 samples per second.

\section{Results}

The experimental Torque versus Rotational Displacement curves were used to determine the maximum values of torque for each of the 20 combinations of Shoe Type and Playing Surface. It was found that generally the torque also increased as the shoe being tested was changed as follows: Round Studded, Turf Shoe, Bladed Studded and Soft Grounds (Table 1). Generally, the torque increased as the playing surface varied in the following order: Gym Turf, Old Turf, Grass, New Turf 1.5" and New Turf 1.0" (Table 2).

This maximum torque data was imported into the statistical software package JMP Pro by SAS Inc. First a regression analysis was performed on the data to determine which factors and corresponding higher order interactions were of significance. It was found that both Shoe Type and Playing Surface had significant effects on the maximum torque with resulting $\mathrm{P}$-values less than 0.05 for certain combinations. The significance between certain combinations of factors is easier to interpret visually in Fig. 8 and 9.

Table 1. The mean maximum torque values calculated from the 25 tests performed by each shoe type

\begin{tabular}{lcl}
\hline Shoe Type Mean Maximum Torque Values & \\
\hline Round Studded & $53.9 \mathrm{~N}-\mathrm{m}$ & $477 \mathrm{in}-\mathrm{lbs}$ \\
Turf Shoe & $58.4 \mathrm{~N}-\mathrm{m}$ & $517 \mathrm{in}-\mathrm{lbs}$ \\
Bladed Studded & $64.8 \mathrm{~N}-\mathrm{m}$ & $574 \mathrm{in}-\mathrm{lbs}$ \\
Soft Grounds & $70.5 \mathrm{~N}-\mathrm{m}$ & $624 \mathrm{in}-\mathrm{lbs}$ \\
\hline
\end{tabular}

Table 2. The mean maximum torque values calculated from the 20 tests performed on each playing surface Playing Surface Mean Maximum Torque Values

\begin{tabular}{lll}
\hline Gym Turf & $42.7 \mathrm{~N}-\mathrm{m}$ & 378 in-lbs \\
Old Turf & $54.2 \mathrm{~N}-\mathrm{m}$ & $480 \mathrm{in}-\mathrm{lbs}$ \\
Grass & $62.8 \mathrm{~N}-\mathrm{m}$ & $556 \mathrm{in}-\mathrm{lbs}$ \\
New Turf 1.5” & $69.8 \mathrm{~N}-\mathrm{m}$ & $618 \mathrm{in}-\mathrm{lbs}$ \\
New Turf 1.0" & $79.3 \mathrm{~N}-\mathrm{m}$ & $702 \mathrm{in}-\mathrm{lbs}$ \\
\hline
\end{tabular}




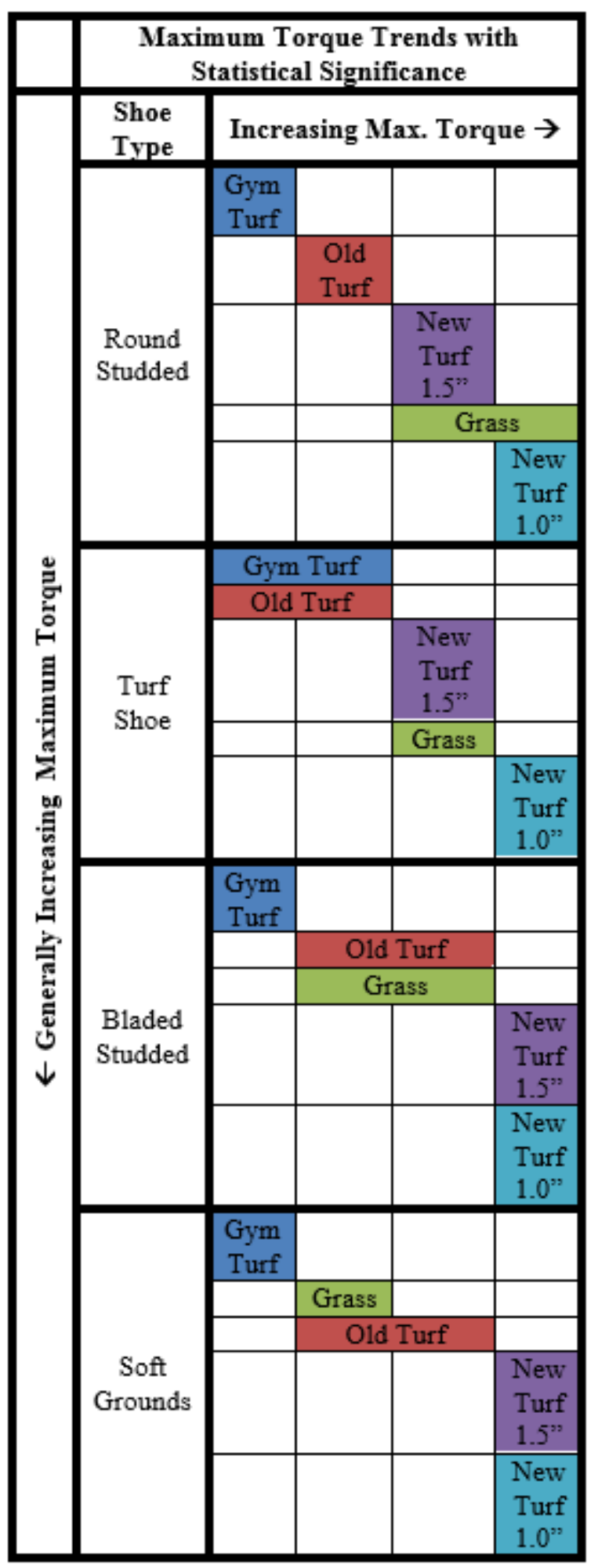

Fig. 8. The general trends for increasing torque for each combination, organized by shoe type and how the values statistically differ. Areas where the colored boxes overlap represent combinations that are not statistically different from each other

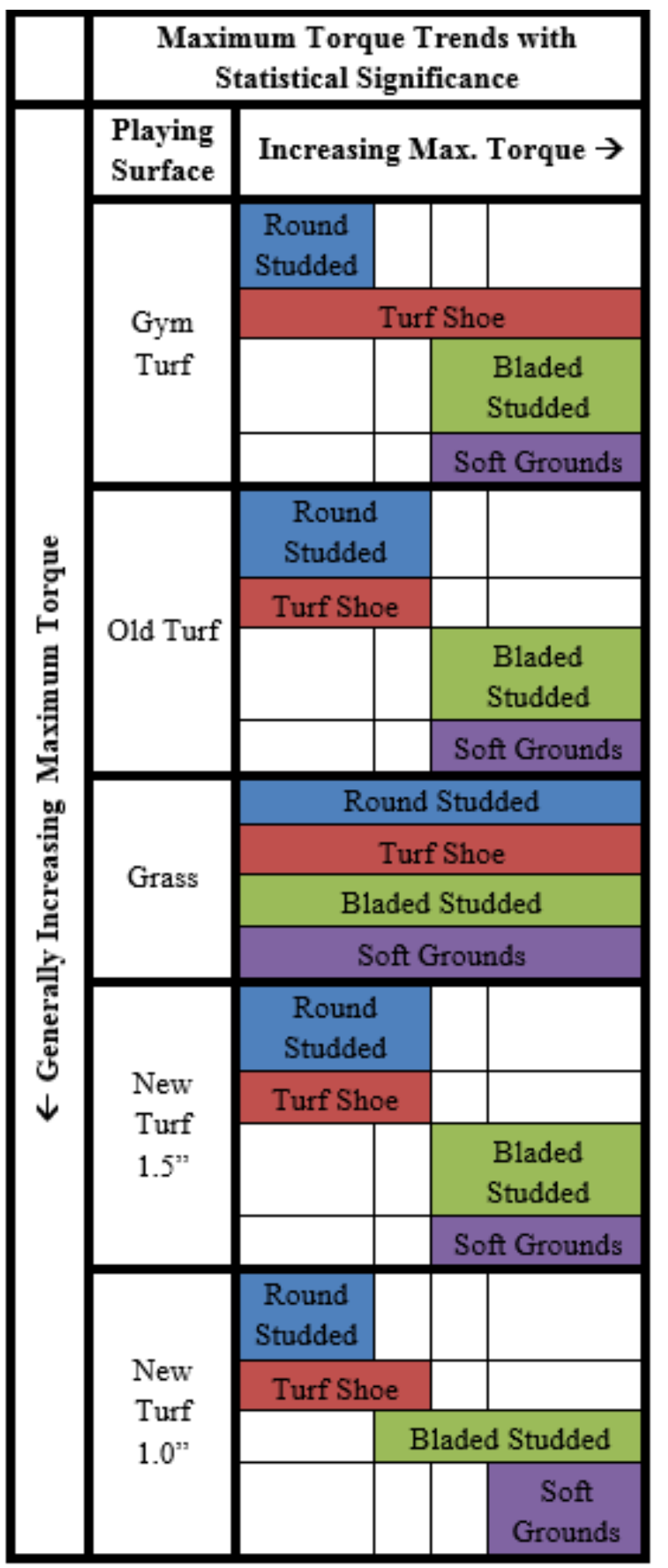

Fig. 9. Shows the general trends for increasing torque of each combination, organized by playing surface and how the values statistically differ. Areas where the colored boxes overlap represent combinations that are not statistically different from each other

The impact of Shoe Type and Playing Surface on maximum torque was further evaluated using a BoxWhisker Plot (Fig. 10). This plot visually shows the trend of increasing maximum torque as follows: Gym Turf, Old Turf, Grass, New Turf 1.5" and New Turf 1.0". 


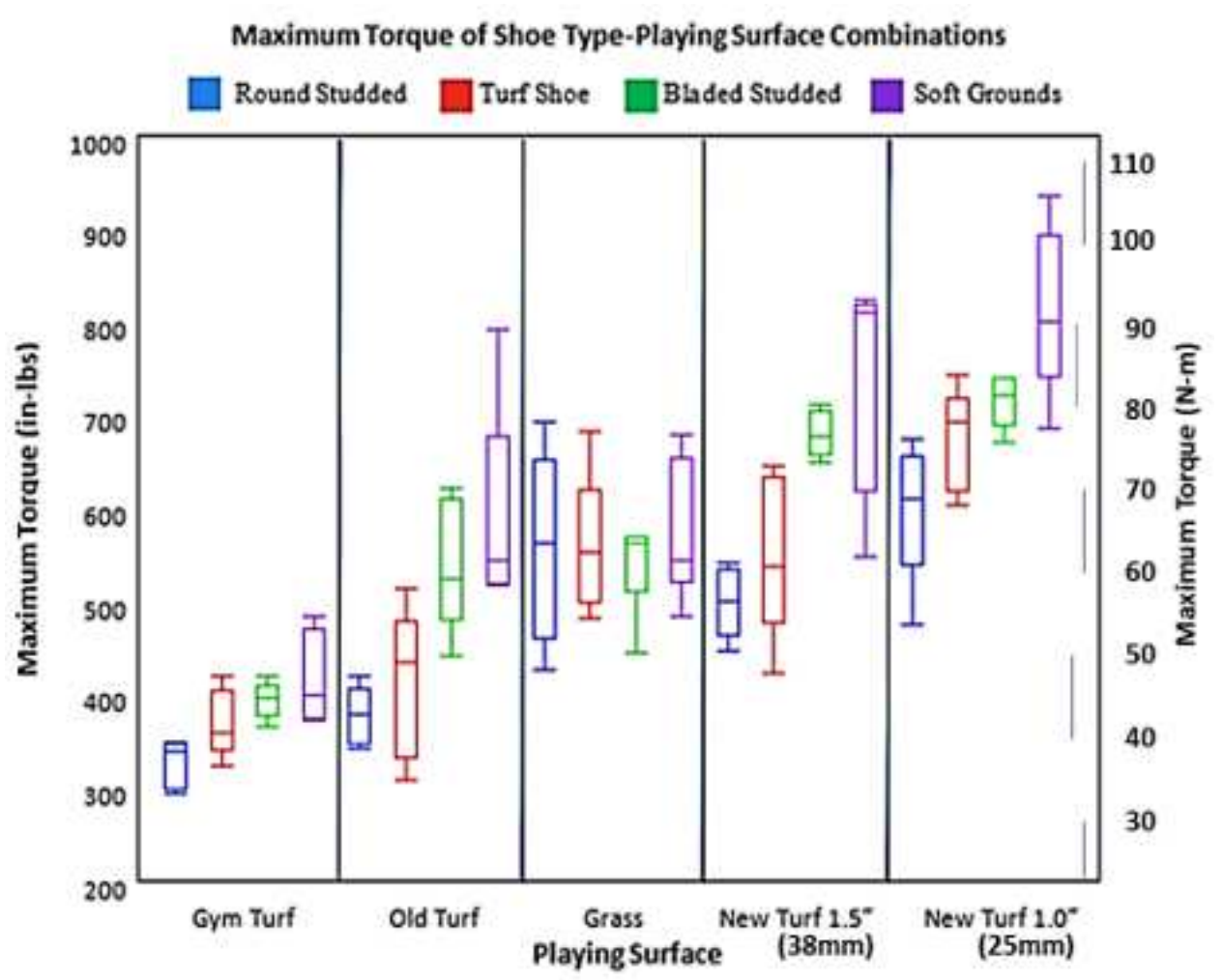

Fig. 10. Shows the general trends for increasing torque among the various Shoe Type and Playing Surface combinations

It also shows that the maximum torque increased by shoe type as follows: Round Studded, Turf Shoe, Bladed Studded and Soft Grounds. This was true on all surfaces except Grass where all shoes experienced statistically similar maximum torque values.

\section{Discussion}

\section{Shoe Type}

There are many types of soccer cleats currently on the market. This study generalized all of these cleats into four types that produced maximum torque values that increase as follows: Round Studded, Turf Shoe, Bladed Studded and Soft Grounds. Certain shoes are not designed to be played on some surfaces they were tested on, such as turf shoes on grass and soft ground cleats on artificial turf; however, they were tested anyways to obtain complete sets of data.

Round Studded cleats and Turf Shoes experienced statistically similar maximum torque values on all playing surface samples. The Round Studded cleats were fairly worn down which could be the reason that they produced similar torque to Turf Shoes, which were hypothesized to produce the least amount of torque. Another explanation for the low torque values could be due to the rounded shape of the studs which allow the shoe to turn more easily in the playing surfaces compared to Bladed Studded cleats. In addition, Turf Shoes have small ridges on the bottoms, not studs, which allows the shoes to grip but not get "stuck" in the playing surfaces.

Bladed Studded cleats and Soft Grounds also produced statistically similar maximum torque values on all of the playing surfaces; however, these values were greater than the torque values experienced by Round Studded cleats and Turf Shoes. As previously mentioned, the difference in torque between Round Studded cleats and Bladed Studded could be due to the shape where a rounder shape stud allows the shoe to rotate more easily compared to longer bladed studs. In addition, the differences in torque between Round Studded cleats and Soft Grounds which both have rounded studs could be due to the depth of the studs. Soft Grounds have much deeper studs that increase the surface area in contact with the playing surface, increasing traction and maximum torque experienced by the shoe.

\section{Playing Surface}

There are many factors that are involved in choosing a playing surface: Cost of installation and maintenance, resistance to weather change, versatility, amount of time it can be played on, quality and consistency of the surface, how the surface feels to the players and traction. Traction is necessary for players to perform maneuvers 
during game play; however, too much traction can lead to increased torque on the knee, putting players at a higher risk for injury.

This study determined that generally the maximum torque experienced by the shoe increased in the following order: Gym Turf, Old Turf, Grass, New Turf 1.5" and New Turf 1.0". Gym Turf is thatched turf with $1 / 2$ " blades and foam backing which is commonly used in gym/performance centers. This surface does not contain rubber infill, leading to low traction that causes players to slip. Although this surface experienced the lowest torque and would be the best option to reduce ACL injuries, players would not be able to perform maneuvers in game like conditions. In addition, it does not contain rubber infill to provide cushion which could result in more impact related joint injuries if played on frequently.

Old Turf represents ten-year-old slit film artificial turf surface with a small amount of rubber infill that was used in an indoor soccer facility. The slit film turf blades and rubber infill provide more traction than that of Gym Turf while causing a relatively low torque on the body. This surface provides the traction needed for game play; however, similar to Gym Turf, the surface is considered to be "hard" which could cause impact joint injuries and discomfort in players.

Grass represents Kentucky bluegrass samples grown in $50 \mathrm{~mm}$ ( 2 in.) of soil. This study shows grass has more traction than Gym Turf and Old Turf but less than the New Turf samples. In addition, it was found that the maximum torque experienced by each shoe on Grass was statistically the same. This shows that Grass provides enough traction for maneuvers in games and it deforms as needed so the torque levels don't exceed a threshold value around $2450 \mathrm{~N}(550$ in-lbs). In other words, the Grass samples acted like a torque neutralizer between all the different shoe types. Grass acts as an ideal surface, providing cushion to decrease impact on joints, the traction needed for game play and having the ability to deform so a threshold torque value is not exceeding which would stress the ACL.

New Turf 1.0" and New Turf 1.5" are new slit film artificial turf samples with $25 \mathrm{~mm}$ (1.0 in.) and $38 \mathrm{~mm}$ (15 in.) rubber infill depths. Both of these surfaces generally produced a higher maximum torque than the previous three samples; however, the $38 \mathrm{~mm}$ (1.5 in.) rubber infill depth had less torque than the $25 \mathrm{~mm}(1.0$ in.) depth. This difference could be due to wear on the surface because the $38 \mathrm{~mm}$ ( $1.5 \mathrm{in}$.) tests were conducted on the same sample as the $25 \mathrm{~mm}$ (1.0 in.) were previously. A more probable explanation is that the increased rubber depth allowed the playing surface to deform more, reducing the torque produced. Since the artificial turf fibers do not rip out or deform easily, it is possible to decrease the torque by reducing contact with the fibers by adding more rubber infill; however, adding too much infill may affect traction and game play.

\section{Conclusion}

After considering the torque and feel of the surfaces on players' bodies, the ideal combinations of shoe type and playing surface can be determined. According to the data collected, wearing round studded cleats or turf shoes on old artificial turf surfaces provides the best traction for maneuvers in games while still allowing the shoe to slip out when dangerous torque levels are reached. On the other hand, bladed studded cleats or soft grounds on new turf without adequate rubber infill results in too much traction that can result in injury to the players.

Gym Turf does not provide enough traction or cushion for athletes and should not be installed for game play. Old Turf provides the traction needed for game play while producing relatively safe torque values; however, the surface does not have cushion needed to limit impact joint injuries. The New Turf samples contained enough rubber infill to provide cushion and traction, but the torque experienced was much greater than the other turf samples. The torque experienced on natural grass falls in between these two extremes and is not affected significantly by the type of shoe worn.

Natural grass provides all the benefits of cushion, traction and the ability to deform in order to reduce injuries. Based on these three criteria, playing on natural grass with round studded cleats is recommended; however, in the modern athletic domain avoiding playing on artificial turf surfaces is difficult. To limit stress on the ACL when playing on artificial turf surfaces, wearing turf shoes or round studded cleats is recommended. Ideally, these recommendations along with other data presented in this report can help prevent ACL tears in soccer players by helping them choose appropriate footwear for the surface on which they are playing.

\section{Acknowledgement}

We would like to thank Albany Medical College for donating the SACH type prosthetic foot to the Mechanics Lab at Union College (Schenectady, NY).

\section{Funding Information}

There were no significant financial contributions made to this study.

\section{Author's Contributions}

Melissa M. Mansfield: Contributed to the conception and design of the experiment; the acquisition, 
analysis and interpretation of the data; drafting the manuscript; and in the critical review process.

Ronald B. Bucinell: Contributed to the design of the experiment; the analysis and interpretation of the data; drafting the manuscript; and in the critical review process.

\section{Ethics}

There are no ethical or financial conflicts of interest regarding the research presented in this paper

\section{References}

ASTM, 2009. Annual book of ASTM Standards. Vol.15.07 End Use Products. Standard test method for traction characteristics of the athletic shoe-sports surface interface. F-2333-04. ASTM, West Conshohocken, PA.,

Box, G.E.P., J.S. Hunter and W.G. Hunter, 2005. Statistics for Experimenters: Design, Innovation and Discovery. 2nd Edn., Wiley-Interscience, Hoboken, ISBN: 0471718130, pp: 633.
Coleman, E., 2011. Statistics on ACL injuries in Athletes. LIVESTRONG.COM.

Griffin, L.Y., J. Agel and M.J. Albohm, 2000. Noncontact anterior cruciate ligament injuries: Risk factors and prevention strategies. J. Am. Acad. Orthop. Surg., 8: 141-150.

DOI: $10.5435 / 00124635-200005000-00001$

Morse, A., R.M. Mansfield, R.M. Alley, H.A. Kerr and R.B. Bucinell, 2016. Traction enhancing products affects maximum torque at the shoe-floor interface: A potential increased risk of ACL injury. Am. J. Eng. Applied Sci.

Serensits, T.J. and A.S. McNitt, 2014. Comparison of rotational traction of athletic footwear on varying playing surfaces. Penn State's Center for Sports Surface Research.

Villwock, M.R., E.G. Meyer, J.W. Powell, A.J. Fouty and R.C. Haut, 2009. Football playing surface and shoe design affect rotational traction. Am. J. Sports Med., 37: 518-525.

DOI: $10.1177 / 0363546508328108$ 